\title{
EL ARCHIVO DE LA CÁMARA DE COMPTOS Y LA BIBLIOTECA DE LA REAL ACADEMIA DE LA HISTORIA. SU VOCABULARIO ANTIGUO
}

\author{
JUAN CARLOS GALENDE DÍAZ \\ ANA MARÍA FERNÁNDEZ HidAlgo
}

Diferentes son las obras que sobre la Cámara de Comptos se han publicado, motivo por el que no pretendemos en las próximas líneas realizar un estudio exhaustivo sobre esta conocida Institución. Más bien queremos presentar una serie de piezas documentales que se encuentran archivadas en la Biblioteca de la Real Academia de la Historia y se hallan directamente relacionadas con ella, y más especialmente una del archivero José Yanguas sobre términos antiguos que aparecen en los documentos conservados en el archivo de Comptos. Por esa razón, en este estudio comenzaremos realizando una breve historia tanto de la Cámara como del Archivo, para luego centrarnos en los documentos citados y terminar con un apéndice en el que transcribiremos la obra del archivero navarro.

A modo de introducción simplemente recordemos algunos momentos en la evolución histórica de este Archivo, que, sin duda. constituye la sección más rica del Archivo General de Navarra, y que está constituida tanto por los fondos del antiguo Archivo Real, como los que afectan a la vida hacendística del Reino y correspondían más concretamente a la Cámara de Comptos Reales; fusión que se inicia, al parecer, en el siglo XIV.

Tradicionalmente, como nos manifiesta José $\mathbf{M}^{2}$ Lacarra ', se ha admitido que el castillo de Tiebas sirvió como depósito del Archivo de la Cámara de Comptos y del Archivo Real, pero nunca fue centro único de recogida de las viejas memorias del Reino, por lo que a pesar de sufrir diferentes incendios en los siglos XIII y XIV, no serían demasiado importantes las pérdidas. Sabemos

' J.R. Castro, Catálogo de la Sección de Comptos, I, Pamplona, 1952, pp. 5-25. Durante las páginas citadas se extiende la introducción a esta ingente obra, que fue realizada por J.M. LACARRA 
que en 1328 existían tres lugares destinados a ser depósitos documentales: Tiebas, Estella y Pamplona; el primero era donde se guardaba la documentación del Archivo Real y de la Tesorería -luego Cámara de Comptos-, y que era posterior al siglo XII, según podemos estimar. Sobre el estado de los archivos del Reino, en enero de 1328, el notario Martín Pérez de Cáseda, auxiliado por Pierres Lapreste y Juan García de Estella, hicieron un minucioso inventario, correspondiendo a los documentos privados de Tudela el honor de ser los más antiguos del actual Archivo de Comptos, y que se encontraban depositados en Estella.

Posteriormente, en tiempos de Carlos II, se reorganizó la Cámara de Comptos como un Tribunal permanente, con 4 oidores y 2 oficiales ${ }^{2}$. Más tarde, durante el siglo XV, la Cámara y su archivo ya no estaban ubicados en la calle Mayor de la Navarrería, sino en una casa del Rey, detrás de la iglesia de San Cernín, pero el derrumbamiento del edificio originó la pérdida de muchos fondos. No sería hasta 1524 cuando quedó instalada la Cámara, y con ella su archivo, en un edificio de la calle de Tecenderías. Allí se fue guardando toda la documentación, sin grandes ánimos clasificatorios, por lo que en 1734 el Tribunal de Comptos informaba al regente del Consejo del mal estado en que se encontraban los documentos del Archivo, apiñados y revueltos.

Un primer intento para coordinar el Archivo se produjo cuando en 1749 el párroco de Egüés, Bernardo Sanz, y su escribiente, Joaquín de Narcué, comenzaron a inventariar la documentación. Pero no sería hasta 1780 cuando se llevó a cabo una verdadera labor de ordenación y catalogación metódica de los fondos del Archivo de Comptos, destacando en esta labor el P. Liciniano Sáez, monje benedictino de Litos, quien trabajó durante más de 3 años, confeccionando un catálogo en 29 tomos.

Sin embargo, por causa de la guerra mantenida con la República Francesa, y ante el temor de un saqueo en Pamplona, se tomó la medida precautoria de instalar el Archivo en el noviciado de los carmelitas descalzos de Corella, donde permaneció sólo unos días.

Durante la centuria decimonónica, el Tribunal de la Cámara de Comptos siguió las oscilaciones producidas por las variaciones de la política. Así, en 1820 -8 de mayo- fue suprimido; en 1823 se restableció. En 1833 se ordenó no proveer las vacantes que se fuesen produciendo en el Tribunal, hasta que se extinguiese por si mismo. Luego, el 24 de marzo de 1834, el virrey accedía a la solicitud de la Diputación de encargarse de la custodia del Archivo de la

2 Para el conocimiento de la Cámara en esta etapa es interesante la obra de J. ZUNZUNEGUI, El reino de Navarra y su obispado de Pamplona durante la primera época del Cisma de Occidente, San Sebastián, 1942. Una aportación más reciente sobre esta Institución es el imprescindible estudio de M." P. HUICI, La Cámara de Comptos de Navarra entre 1328-1512, con precedentes desde 1258, Navarra, 1988. 
extinguida Cámara de Comptos Reales de este Reino, aunque de manera efectiva no se realizó hasta el 23 de diciembre de 1836.

El Archivo continuó en los locales de la calle de Tecenderías, -donde fueron consultados por el archivero de la Diputación José Yanguas y Miranda-, hasta 1852, fecha en que fue trasladado al Palacio Provincial, y quedó instalado en el $2^{\circ}$ piso junto con el Archivo de Cortes.

No sería hasta finales del siglo pasado cuando se proyectó construir otro edificio para cobijar, juntamente con el Archivo Vivo de la Diputación Foral, todos los archivos históricos que se le incorporaban. El edificio actual, proyectado por el arquitecto Florencio Ansoleaga, se comenzó a construir en 1896, instalándose los Archivos en 1898. Posteriormente tuvo que ser ampliado al recibir más documentación '. En él se encierra la historia entera de Navarra 4 .

Respecto a la Cámara de Comptos de Navarra, apuntar como hitos históricos más importantes que su estilo vino con el primer príncipe francés que reinó en Navarra: Teobaldo I de Champaña. En esa región, quizás por esta época (1234), las comisiones con encargos de hacienda se habían convertido en oficio. Después, hacia 1240, Teobaldo IV sustituye, según el historiador francés Longnon, los «chambriers» por recibidores. En Navarra existen en el siglo XIII libros de «comptos» de factura gala'.

Luego Carlos II de Navarra, en torno a 1365, promulga su Ordenanza de reorganización de esta Institución. Debía estar compuesta, según dijimos antes, por 4 oidores y 2 clérigos $^{6}$; además, el monarca fija sus atribuciones y jurisdicciones.

Desde 1364, la Cámara, constituida por el poder real, tenía gran actividad, habiendo adquirido cierta independencia; únicamente tenía por encima al Consejo y al Rey, y algunos oidores solían formar parte del Consejo.

Será Carlos III quien cree el cargo de procurador patrimonial, a modo de brazo largo de la Cámara. Por su parte, el tesorero, que ya existía antes de 1364 y que parece estaba a la cabeza del escalafón, queda después como colaborador

' J.R.CASTRO, op. cit. I, pp. 5-28

4 Sobre este archivo y sus fondos, además del Catálogo de la Sección de Comptos (dirigido en sus dos etapas por J.R. CASTRO y F. IDOATE), son interesantes las obras de J.A. BRUTAILS, Documents des archives de la chambre des comptes de Navarre (1196-1384), París, 1890 y F.J. ZABALO, El registro de Comptos de Navarra en 1280, Pamplona, 1972. Asimismo, sobre la sección de Comptos se puede consultar el Catálogo de los Sección de Comptos: documentos (Archivo General de Navarra, Departamento de Educación y Cultura, Pamplona, 1985) y el Indice de Materias. Sección de Comptos (Archivo General de Navarra, Pamplona, 1972).

M. P. HUICI, Camara de Comptos de Navarra, Pamplona, 1983, p. 1

' Se denominaban así a aquellas personas que desempeñaban servicios auxiliares, fuesen clérigos o no; quizás lo fueron en algún tiempo. 
de los oidores, con atribuciones judiciales y teniendo que rendir cuentas a los maestros de comptos.

Más tarde, y debido a la guerra civil desatada en 1456 entre agramonteses y beamonteses, se desorganiza todo lo existente. Don Juan tendrá una Cámara en Sangüesa y el Principe de Viana otra en Pamplona. El patriotismo se destruye. Al final de la centuria preocupa su reconstrucción, pero la Cámara parece participar en la decadencia.

En el siglo XVI, y debido a los sucesos de 1512 con la anexión a Castilla, la situación es diferente. Esta Institución es respetada, elaborándose Ordenanzas por los visitadores, que tienen en cuenta las anteriores.

En 1679 surge el primer intento de supresión, apoyando su desaparición las Cortes y el Virrey, pero la ciudad de Pamplona se opone, logrando que prosiga; luego, los tres Estados y la Diputación defienden su permanencia.

Durante la centuria siguiente sufrirá golpes mortales. Así, en 1748 el Rey le quita la administración de las tablas. Años después modifica la manera de hacer el donativo: hasta este momento la Cámara había organizado siempre el repartimiento de cuarteles y alcabalas que concedían las Cortes; luego será el Rey quien los otorga como reintegro de lo que ha cobrado en efectivo. De esta manera, con enormes problemas, se llega a 1820 , fecha en que por disposición ministerial es abolida, aunque se restablece tres años después. Finalmente es suprimida de forma definitiva el 6 de marzo de 1836, permitiendo a la Diputación recoger el archivo. Concluía, por el momento, la historia de este Tribunal de Cuentas del Reino; tribunal de hacienda y tribunal real.

La documentación demuestra que fueron tutores del patrimonio real, conservadores y administradores de sus bienes; asesoraban, a petición del monarca, sobre la conveniencia o no de un arrendamiento, de una permuta, de la creación de nuevos impuestos, de la legitimidad de un privilegio, etc., es decir, de toda operación que alterara el patrimonio de alguna forma. Asimismo, aunque el Monarca y el Consejo tomaban las decisiones importantes, la Cámara cuidaba de su realización. Podía juzgar y sentenciar en primera instancia los delitos cometidos contra el patrimonio real, que era el Tribunal Supremo de Navarra?

No será hasta tiempos actuales cuando sea reinstaurada por una norma del Parlamento Foral navarro. Esto sucedió el 6 de febrero de 1980, aunque en la práctica comenzó sus actuaciones en mayo de 1982. Es la encargada de fiscalizar las finanzas del sector público, pero no tiene poderes judiciales.

Analizada sucintamente la evolución de estos organismos, centrémonos en aquellas piezas documentales que se encuentran en la Biblioteca de la Real

M. ${ }^{a}$ P. Huicl, op. cit., p. 3. 
Academia de la Historia ${ }^{*}$ y tienen una relación directa con el Archivo de la Cámara de Comptos navarro.

En primer lugar tenemos que referirnos a dos volúmenes manuscritos que llevan por título Documentos sacados del Archivo de la Cámara de Comptos de Navarra. Indice de los mismos ". El autor es José de Vargas y Ponce, quien al final de cada uno de ellos estampa su firma y rúbrica "Joseph de Vargas y Ponze». Se trata de dos tomos con idénticas características externas $(325$ x 220mm) escritos con tinta negra de forma opistógrafa sobre papel, estando confeccionados por la unión de diferentes pliegos doblados o bifolios puestos unos detrás de otros. Las cubiertas se encuentran encuadernadas con cartón, llevando un refuerzo de cuero en el lomo y puntas para protegerlas; por su parte, en el lomo encontramos 5 nervios, habiéndose grabado con caracteres capitales entre los tres primeros: "Archivo de la Camara de Comptos de Navarra. Extracto de Indices. Tomo I» (en el segundo pone "tomo II»). En ellos, redactado con escritura humanística cursiva del sigio XVIII, el autor transcribe seguidos documentos que juzgo útiles para las tareas de la Real Academia de la Historia. De esta manera, Vargas Ponce, en el primer volumen extracta autógrafamente 739 documentos fechados desde el año 1231 al 1400, mientras que en el segundo el total es de 1.106, datados entre los años 1123 y $1511^{10}$. A través de los folios ( $305 \times 210 \mathrm{~mm}$.) de cada manuscrito, el autor va agrupando los documentos que compendia según el tomo del índice del Archivo de la Camara de Comptos del que los haya obtenido, siendo el total de 29 tomos ( 14 en el $1^{\circ} \mathrm{y}$ 15 en el otro). La forma de presentarlos es muy sencilla: copia el extracto de los

${ }^{8}$ Esta Institución, fundada por Felipe $\mathrm{V}$ en 1713, atesora unas 100 grandes colecciones de temática diferente (algunas con un valor inapreciable por ser únicas en su contenido), unos 250 manuscritos de los siglos VIII y IX, unos 150 incunables, numerosas obras impresas en el siglo XVI y otras selectas. En total se puede calcular que conserva unos 250.000 volúmenes impresos y 10.000 manuscritos.

9 Biblioteca de la Real Academia de la Historia, sign. 9/5720 y 9/5721 (antigua D.110 y D.111)

11 La temática de estos documentos no es concreta. Así podemos comprobar como extracta, entre otros, los documentos que versan sobre la confederación entre los reyes de Navarra y Aragón (1254), donación de Alonso de Castilla el Sabio al rey Navarro Teobaldo de las villas de San Sebastián y Fuenterrabía (1256), bula de Nicolás III confirmando al monasterio de Leire sus posesiones (1279), artículos acordados en las paces entre Navarra e Inglaterra (1308), juramento del rey francés Felipe y su mujer Juana como monarcas de Navarra (1319), libro titulado Del monedage de la ciudad de la Navarreria de Pamplona (1350), organización de la Cámara de Comptos (1364), el derecho de la saca de vino (1379), creación del puesto de alferez del reino de Navarra en Carlos Beaumont (1379) y del de chanciller en Mosen Frances (1396), hermandad realizada entre Navarra, Alava y Guipuzcoa en 1368 y renovada en 1407, homenaje del obispo de Calahorra al rey de Navarra (1412), testamento de Carlos III de Navarra (1412), bula de Martín V concediendo dispensa a Blanca de Sicilia para contraer matrimonio con cualquier consanguíneo, linajes, etc. 
documentos uno a continuación de otro, dejando un pequeño espacio en blanco entre ambos; además, a modo de nota en el margen izquierdo, redacta un sencillo regesto de cada documento.

El estado de conservación en que se hallan estos ejemplares es bueno, aunque el $1^{\circ}$ de ellos tiene algún folio roto, debido a la humedad. Sus folios están sin numerar (únicamente el inicial tiene los 80 primeros numerados con dígitos arábigos modernos en su extremo inferior derecho), y en ellos la escritura es clara, ligada, de módulo mediano, con buena separación de palabras y, por lo general, sin abreviaturas, teniendo cada página 23 renglones. Por su parte, los márgenes tienen las dimensiones siguientes, tanto en los rectos como en los versos: el superior y el inferior es de $20 \mathrm{~mm}$, el lateral izquierdo es de 40 a $60 \mathrm{~mm}$ y el lateral derecho es nulo.

En cuanto a la fecha de composición de esta obra, hay que datarla a finales del siglo XVIII y comienzos de la centuria siguiente, ya que la única data que aparece la localizamos al final del $2^{\circ}$ volumen, junto a la rúbrica y firma del autor: 1805.

¿Y cómo llega esta información a José Vargas Ponce? La solución la encontramos en otra pieza documental que hemos encontrado en el ArchivoBiblioteca citado. Nos estamos refiriendo a una misiva enviada por Joaquín Juan de Flores a Vargas Ponce el 27 de enero de 1806. En ella, escrita autógrafamente en 5 bifolios de papel, Joaquín J. de Flores extracta una serie de documentos que remite a Madrid. Aunque tiene algunos dobleces, esta carta se conserva en buen estado, siendo su contenido el siguiente:

«Por la via reservada de Marina, como todos los anteriores, remito a V.S. para que tenga a vien de presentarlos a nuestra Real Academia 3 pliegos que contienen 17 extractos del tomo XXIX del Archivo de esta Camara de Comptos, $2^{\circ}$ del Indice de los Cartularios y ultimo del indice General.

Con estos pliegos se completan los 395 que en quince remesas desde primeros de octubre he dirigido a V.S., y son los 1845 extractos que contienen quantos segun mi pobre juicio son dignos de la atencion de la Academia" ".

Hasta aquí todo lo relativo al primer asunto tratado. En relación directa con él, centrémonos a continuación en el segundo, que es el referente al vocabulario empleado por esta Institución. Para ello, nada mejor que acudir a una fuente directa, cuál es la del insigne navarro José Yanguas y Miranda sobre

"Biblioteca de la Real Academia de la Historia, sign. 9/4218. Esta signatura corresponde al tomo 45 de la colección de José Vargas Ponce, quien la donó a este Centro en 1821 después de fallecer. Está compuesta por 82 tomos, de los que 24 son en octavo; en ellos se continen numerosos documentos de temática diferente sobre Geografía e Historia de España, especialmente referentes a las provincias vascongadas. 
los términos aparecidos en documentos del Archivo de Comptos "2. Esta pieza documental, inserta en un legajo que contiene documentación relativa a diversos archivos, consiste en un cuadernillo de papel compuesto por 14 bifolios cosidos lateralmente ( 25 folios escritos opistógrafamente, más dos en blanco y uno dedicado a portadilla). En él, escrito autógrafamente por Yanguas con tinta de color sepia oscura, encontramos un vocabulario sobre el tema citado, donde las voces aparecen ordenadas alfabéticamente. La escritura empleada por Yanguas en su confección es humanística cursiva, muy cuidada, dextrógina, ligada y de tamaño mediano. En cuanto a las dimensiones absolutas de cada folio, apuntar que son 315 x $220 \mathrm{~mm}$, estando en cada uno de ellos los márgenes bien respetados: $30 \mathrm{~mm}$ el superior, el inferior y el lateral derecho, mientras que el lateral izquierdo es de $40 \mathrm{~mm}$. Por lo que concierne a la fecha de realización de esta interesantísima obra, hay que datarla en 1853; es más, al final de ella, además de firmar y rubricar, José Yanguas y Miranda adjunta la data tópica y cronológica de finalización de su trabajo: Pamplona, 21 de febrero de 1853.

Antes de transcribir su obra, creemos que es interesante dedicar unas líneas a la biografía de José Yanguas y Miranda ${ }^{13}$. Este ilustre archivero nació en tiempos del despotismo ilustrado, el 15 de marzo de 1782. Fue miembro de la Real Sociedad de Anticuarios del Norte de Copenhague, miembro correspondiente de la Real Academia de la Historia, socio de la Sociedad de Anticuarios del Oeste de Francia, socio de mérito de la Sociedad Arqueológica de Madrid y Archivero de Navarra, cargo concedido por la Diputación en 1830. Falleció el 25 de septiembre de 1836 a la edad de 81 años ${ }^{14}$. Durante su vida, la labor erudita fue muy fecunda, trabajando especialmente en la elaboración de diccionarios relativos a su tierra natal; así podemos mencionar el Diccionario bistórico político de Tudela (Zaragoza, 1823), Diccionario de los Fueros del Reino de Navarra (San Sebastián, 1828), Diccionario de antigüedades del Reino de Navarra (4 volúmenes, Pamplona, 1840) y Diccionario de las palabras anticuadas que contienen los documentos existentes en los archivos generales y municipales de Navarra (Pamplona, 1854). Además también es obligatorio citar otras tres obras importantes de este erudito: Historia compendiada del Reino de Navarra (San Sebastián, 1832), Análisis histórico crítico de los Fueros de Navarra (Pamplona, 1838) y Manual para Gobierno de los apuntamientos de Navarra (Pamplona, 1846) '.

12 Biblioteca de la Real Academia de la Historia, sign. 9/6270, núm. 14.

13 Sobre su figura existen publicadas diferentes obras, entre las cuales podemos citar las de J.R. CASTRO, Yanguas y Miranda. Una vida fecunda al vaivén de la politica, Pamplona, 1963, y J.M." IRIBARReN, Yanguas y Miranda (su vida y su obra), Pamplona, 1963

${ }_{14}$ J.R. CASTRO, Yanguas y Miranda, Pamplona 1981.

is De estas obras se han reeditado prosteriormente, quizás las más importantes: 
Visto este breve apunte biográfico, pasemos, como conclusión de este estudio, a la transcripción de esta obra de José Yanguas, en la que advierte lo siguiente:

«Como el principal objeto de este Diccionario es el de facilitar la inteligencia de los documentos del archivo de Comptos, se han copiado literalmente las voces que contienen, á pesar de que algunas de ellas parecen sinónimas, y puede consistir, ya en error de los escribientes, y ya en las alteraciones que debió sufrir el lenguaje en las diferentes épocas á que pertenecen dichos documentos».

Para llevarla a cabo hemos pensado que lo más conveniente es mantener la grafía original del autor, corrigiendo, únicamente, los errores ocasionados por descuidos. Veamos el citado vocabulario:

«Diccionario de las palabras anticuadas que contienen los documentos existentes en el archivo de Comptos de Navarra, y de su correspondencia con el lenguage actual».

A

- AbARCa (infanzón de) $=$ Cierta clase de labradores que á pesar de ser pecheros, se consideraban como nobles.

- ABASTAR = Abastecer, suministrar. Ser Suficiente.

- ABEILLA = Abeja.

- ABENIENZA = Pacto, convenio, concordia.

- ABERSARIO = Contrario, enemigo.

- ABEURAR = Dar de beber a las caballerias y ganados.

- ABNUDA ó ANUBDA = Cierta pecha ó contribucion, cuyas circunstancias no se esplican.

- ABONDAR = Ser bastante ó suficiente.

- ABONDO = En abundancia.

- ABONESCER = Abonar.

- ABONIR = Lo mismo que abonescer.

- ABOYENDOSE = Abonándose.

- ACACERIA = Plaza de mercado.

- ACEMBLA = Acémila.

- ACONDUCHAR = Alimentar, proveer de víveres.

- ACORRER = Socorrer.

- ACOTADO = Desterrado, fugitivo, perseguido por la justicia

- ACOYER = Acoger, albergar.

Diccionario de los Fueros del Reino de Navarra y de las leyes promulgadas hasta las cortes de los años 1817 y 1818 inclusive, Pamplona, 1964, y Diccionario de antigïedades del Reino de Navarra, 3 vols., Pamplona, 1964. 
- ACUILLIR = Lo mismo que acoyer.

- ACUITRAR = Arar, labrar las tierras.

- ACHAQUIA = Pretesto, oposicion, embarazo, queja.

- ADAINAR = Dañarse.

- ADUAR = Adunar, juntar, reunir.

- ADUGAR = Traer, llevar.

- ADULA = Periodo, durante el cual se repartian por dias ó por horas las aguas de regadio entre las tierras que tenian derecho á regarse; usábase particularmente en los campos de Tudela.

- ADUN = Aun.

- ADUSIR = Aducir.

- AFEILLAR = Abortar.

- AFILlAR = Prohijar.

- AFOllAR = Hablando del vino, significa perderse, volverse .

- AFRUENTA = Deshonra, daño.

- AFruentAR = Causar deshonra, daño. Confinar, lindar.

- AFRUENTO = Peligro, daño.

- AFUILlAR = Manchar los vestidos, echar manchas.

- AGARDAR = Guardar, cumplir una obligacion.

- AGERIZAR = Admitir ganados estraños que no tenian derecho al pasto de las yerbas del comun.

$-\mathrm{AGOA}=$ Agua, rio.

- Aibullon = Arbellon, albañal, conducto.

- Ailo ó AIllo = Ajo.

- AILLENAR = Enagenar .

- AILleno ó AILlen = Ageno.

- AILLENT = De la parte de allá.

- AINAL = Añal.

- AINNADER = Añadir.

- AISADA ó ARSADA = Azada.

- AISADERO ó AIXADERO = Simple jornalero sin mas que la azada.

- AL (lo) = Lo demas.

- Alargamiento = Dilacion de tiempo.

- ALCACERIA ó ALGACERIA = lo mismo que acaceria.

- ALCAIT = Alcaide de castillo.

- ALDACA = Pecha de la espalda de cada carnero que pagaban los moros del pueblo de Fontellas.

- Aleviamiento = Alivio.

- AlfaERES = Nombre que se daba en algunas partes á los moros ingenuos ó libres.

- ALFONSADERA = Fonsado, contribucion para la guerra y fortificaciones.

- ALGORIO = Granero.

- AlJUP = Aljibe.

- ALMARIO = Lo perteneciente al sufragio de las almas. 
- AlOGAR = Alquilar.

- AlONGAMIENTO = Alargamiento, prorogacion.

- ALUNGAR = Alongar, alargar, retardar, dilatar.

- ALZA = Alzada, apelacion.

- Allegar ó alleguar = Alegar.

- Allenar ó alCENAR = Lo mismo que aillenar.

- AMERMADO = Mermado, disminuido.

- AMESE = Aconteciese; dado caso que amese ó aconteciese.

- AMETI = Muérete.

- AMIGA = Se decia de las amas de los curas.

- Amigadura = Resarcimiento de daños. El acto de cubrir al macho á la hémbra.

- AMIOS = Ambos, los dos.

- AMOR = Consentimiento, beneplácito, voluntad.

- AMOR (dar) = Consentir, perdonar, convenirse.

- AMORALMENT ó AMORABLEMENT = Amigablemente.

- AMUSARIO = Aniversario por las almas.

- ANAFEGA = Provision de víveres.

- ANNIPNA = Alma.

- ANSARAS = Ansares, aves.

- ANZA = Asta, cuerno.

- AONTADO = Deshonrado.

- APAUTUL $=$ Perverso.

- APEILLIDO = Llamamiento, y particularmente á las armas.

- APENSADAMENT = Con premeditacion.

- APEYORAR = Empeorar.

- APLAURAR = Hablar.

- APLEGAR = Juntar, recoger.

- Apostoligo = Apostólico; el Papa.

- APRENGAR = Aprender, instruir.

- APRESIER = Lo mismo que aprengar.

- APROFAZAR = Aprovechar, utilizarse de alguna cosa.

- AQUEND = Acuende, de la parte de acá.

- ARAILlADO = Rallado; decíase del queso.

- ARANZATICO = Cierta multa perteneciente á los alcaldes por los homicidios.

- ARECHO = Estar derecho ó en pie.

- ARGENTERO = Platero.

- ARIENZO = Medida de tierras de 72 pérticas de longitud y una de latitud.

- ARINZADA, ARANZADA ó ARRANZADA = Medida de vino, como de un cántaro ó carapito; algunas veces se confunde con la medida de tierras llamada arienzo.

- ARNESADO = Caballero bien armado.

- ARQUIAS = Arcos de puente ú de otra fábrica.

- ARRANCADA = Acometida violenta. 
- ARREITAS = De espaldas.

- ARRENCURA = Queja, reclamacion.

- ARRIESQUE $=$ Riesgo.

- ARTILlERIA = Toda clase de armas. Máquinas, artefactos.

- ASADERO = Lo mismo que Aisadero.

- ASADURA = Contribucion ó pecha sobre la cria del ganado.

- ASCUSO ó a ESCUSO = A escondidas, a traición.

- ASEDER = Fijarse, domiciliarse.

- ASEMBLAR = Reunir, juntar, congregar.

- ASEnTAMIENTO = Contrato.

- ASNO SAILLIDOR = Garañon.

- ASTERO = Fabricante de astas de lanza.

- ATA = Hasta tal tiempo, lugar, etc.

- ATAILlAR = Atacar, acometer.

- ATENER = Atenerse á lo prometido, obligado, etc.

- ATERRER = Observar, mantener, cumplir.

- ATREBUDAR = Dar á tributo ó censo.

- ATURAR = Estar, permanecer.

- AU = Ave.

- AUBOLORIO = Abolorio.

- AUgUa = Lo mismo que agoa.

- AVANDITO = Sobredicho.

- AVENIENZA = Avenencia, convenio.

- AVERIAS = Mercancías.

- AYAN = Tengan.

- AYECH = Voz con que los conductores de caballerias debian avisar a los transeuntes para que se retirasen del peligro.

- AYUDA = Contribucion ó subsidio voluntario que las Córtes de Navarra concedian al Rey para los gastos del Estado.

- AZADECA = Pecha que pagaban los moros del pueblo de Córtes sobre los huevos y leche.

- AZADERO = Lo mismo que aisadero.

- AZAguerrico = Cierta pecha que pagaban los pueblos de la montaña de Navarra.

- AZEMBLA = Lo mismo que acembla.

- AZES $=$ A censo.

- AzOFra = Pecha que pagaban los moros del pueblo de Fontellas.

- AzTOR ó ASTOR = Azor.

B

- BAEZA = Nombre sinónimo, segun Sandovál, de Beacia, Beatriz y Sancha.

- BAILIA = Bailio.

- BAGIEILlO = Bodega. 
- BAIS = Bajo, debajo.

- BALADAR = Empalizada.

- BALAT = Foso, cava, zanja.

- BALAX ó BALAI = Piedra preciosa, rubí.

- BALDERO = Baldio.

- BANITO = Bandido, desterrado.

- BANNAR = Bañar.

- BAPTEO = Bautizo.

- BARAIlla = Cuestion, disputa, pleito, querella.

- BARAMIENTO = Engaño, fraude.

- BARATA = Lo mismo que baramiento.

- BARBAZANA = Barbacana, fortificacion.

- BARRAGANA = Concubina.

- BARRAGE = Portazgo.

- BASTIDA = Bastion, casa fuerte.

- BASTIDO = Abastecido.

- BASTO = Pecha muy antigua.

- BATAilla = Batalla, pleito, juicio llamado de Dios.

- Bataillo = Badajo, lengua de campana.

- BATURRATU = Cierta pecha que se pagaba por los herederos de los villanos que morian sin hijos.

- BAUT = Baul.

- BAYART = Color bayo.

- BEACIA = Lo mismo que Baeza.

- BEATRIZ = Lo mismo que Baeza.

- BEDALERO = Especie de guarda de campos, que se conocia particularmente en el pueblo de Arguedas.

- BEGADA = Vez.

- BEIRE = Piel de nutria.

- Beraurdea = Pecha sobre los cerdos que pagaba el pueblo de Auza y se consideraba como deshonrosa.

- BERBEZONES BULliENTES = Gusanos vivos bullendo.

- BERIUS = Uva en agraz y el licor que sale de ella.

- BERMEILlO = Color bermejo.

- BERROILLO = Cerrojo.

- BESTIARIO = El pastor que custodiaba en las yerbas del comun las caballerias de los vecinos de cada pueblo, que hoy se llama dulero, y dula el conjunto de dichas caballerias.

- BISPO = Obispo.

- BLASMO = Acusación, querella.

- BOCERO = Vocero, abogado, procurador.

- BOCLETA = Hebilla.

- BONA = Hacienda, bienes. La legítima de los hijos en la herencia de los padres. 
- BOQUA $=$ Boca.

- BORREL $=$ Berdugo.

- BOTEJAS = Cierta pecha que pagaban los habitantes del valle de Lana.

- BREVEZA = Brevedad.

- BUEY DE COTO = Pena que se imponia recíprocamente en los contratos, debiendo pagar el que los quebrantase tantos bueyes cuantos se estipulaban; cada buey se reputaba por cien maravedis de la moneda de aquel tiempo.

- BUEY OMICIERO = Buey homicida; era todo buey que mataba á otro cualquier animal.

- BUITORNO = Tire bochorno.

- BUREL = Oficina de contabilidad.

- BURULLERO $=$ Tejedor de paños.

- BURUZAGUI ó BURUZAIS = Especie de alguacil.

- BUSTALIZA = Terreno acotado para pasto de bueyes.

- BUSTO = Rebaño vacuno.

- BUY = Buey.

\section{C}

- CABDAL, CAPDAL ó CAUDAL = Grande, principal, hablándose de los rios. Vease seina caudal.

- CABERIA = Caballeria, sueldo que los caballeros que la mandaban recibian del rey; cada caberia se componia de cierto número de caballos.

- CABERO = Caballero, soldado de á caballo.

- CABETME = Deciase, hablando uno de si mismo, pidiendo parte ó ser incluido en algun negocio, y equivale á incluidme, contad conmigo, etc.

- CABO = Cerca, inmediato.

- CABRARIZ = Pastor de cabras.

- CACHONDA = Perra joven, cachorra.

- CADERnio = Cuaderno, libro.

- CAESCIER = Acaecer.

- CAFIZ = Cahiz.

- CAILlIENT $=$ Caliente.

- CALCINA = Cal.

- CALGADA = Cosa llena, apretada.

- CALONIA = Multa.

- CALPE = Golpe; é feriome de doblados calpes con la espada.

- CALZATRIPAS ó CALZATREPAS = Trampa para cazar animales.

- CALZORIO = Calzado.

- CAMARA = Véase Comptos.

- CAMBAS = Piernas, muslos.

- CAMBRA = Cámara, cuarto, aposento. Las rentas del rey y el tribunal de cuentas de las mismas rentas. Vease Comptos. 
- CAMIAR = Cambiar. Caminar.

- CAMIO = Cambio.

- CAMPIX $=$ Hijo adulterino de dos casados.

- CANA = Medida de tela de ocho palmos.

- CANUdo = Canoso.

- CAPDAL = Lo mismo que cabdal.

- CAPITOL $=$ Cabildo, comunidad.

- CAPTADA = Cosa adquirida.

- CAPTENER ó CAUTENER = Abonar, ayudar, salir fiador ó defensor.

- CAR = Pues, porque.

- CARAPITO ó CARABIDO = Medida de vino como de un cántaro.

- CARGUA = Carga, obligación hipotecaria.

- CARNERO = Pecha que bajo este nombre se pagaba al rey por el pasto de sus montes.

- CARNESTULTAS = Carnestolendas.

- CAROSO = Cuidadoso, diligente.

- CARrera = Camino.

- CARTA = Cualquiera escritura.

- CARTAPELO = Cartapacio.

- CASATENIENT $=$ Tener casa o vecindad.

- CASCUN = Cada uno.

- Casticillo = Castillo, pero debia decir al parecer castieillo.

- CAstro = Castillo.

- CAsubla = Casulla.

- CATAR = Considerar, guardar, observar.

- Caudal = Lo mismo que cabdal.

- CAUSA (hobiente) = El heredero ó sucesor que representaba los derechos del difunto. Poder habiente.

- CAUTENEDOR = Abonador, fiador, defensor .

- CAXAL = Quijada.

- CAZADORES = Ciertos pecheros del valle de Esteribar que pagaban al rey una pecha llamada vaca corta, equivalente al parecer á la asadura.

- CEBERA = Cebada y otros granos.

- CEIllero = Cillerero. Bodega, troje.

- CEMITERIO = Cementerio.

- CENA = Pecha semejante á la de salvedat, con la diferencia de que la primera se daba siempre que los señores territoriales pernoctaban en su pueblos, y la segunda el dia en que tomaban posesion de los señores.

- CENIA ó CENEA = Aceña ó molino.

- Cermenage = Contribucion para las fortificaciones de los pueblos.

- CERQua = Cerca, inmediato.

- CINFONIA = Máquina de guerra para armar grandes ballestas. 
- CISA = Sisa, impuesto sobre la venta de comestibles.

- Clamante = Demandante en juicio.

- Clamar a MEANEdo = Comprometer en arbitros.

- ClAMO = Reclamación, querellar.

- Clamor = Lo mismo que clamo.

- Clausari = Cierta pena en que incurria el que insultaba á una villana casada, de manera que cayesen sus tocas en tierra.

- Clausura = Corchete para cerrar los libros.

- Clavero = El casero que los nobles tenian en los pueblos fuera de su residencia para cuidar de sus casas y haciendas; estos claveros eran exentos de contribuciones.

- COA = Cola de animal.

- COCA = Medida de vino.

- $\mathrm{COCHO}=$ Cocido.

- COGNOSCIDO = Reconocido, con todo conocimiento.

- Colllazo ó collazo = El villano ó labrador pechero, y las tierras pecheras.

- CoINADO ó CUINADO = Cuñado.

- COMANDA ó COMIENDA = Depósito.

- COMARQUero = Comarcano, confinante.

- COMEDIO ó COMEYO = Yntermedio ó intérvalo de tiempo, como entretanto, y tambien de lugar; al esplicar el fuero de Navarra cual era la Cuenca de Pamplona, despues de nombrar los pueblos de su circunferencia, concluye diciendo: esticomeyo es la Cuenca de Pamplona; pero téngase entendido que estas palabras están mal escritas, debiendo decir esti comeyo, esto es este intermedio es, ó forma, la Cuenca de Pamplona.

- COMENGAR $=$ Comulgar.

- COMENZO $=$ Principio.

- COMEYO = Lo mismo que comedio.

- COMODAR = Depositar.

- COMPADRASE = Compadrazgo, amistad.

- COMPAINO = Compañero.

- COMPLAINIER ó COMPLANIER = Quejarse, reclamar.

- COMPLAINTA = Queja, reclamacion.

- COMPLECER ó COMPLESCER = Cumplir.

- COMPRESO = Comprenso, incluido, contenido.

- COMPTE $=$ Conde.

- Compto = Cuenta, vease Comptos.

- Comptos (Cámara de) = Tribunal de hacienda de Navarra.

- COMUNAL = Regular; andar al paso comunal.

- CONCA = Medida de granos, equivalente á medio robo de trigo.

- CONCEILlO = Concejo.

- CONCEILLOZO = concejalmente.

- CONDECABO = Ahora, últimamente. 
- CONDIDURA $=$ Comida .

- CONDUCHO = Comida, víveres.

- CONDUITO = Lo mismo que conducho.

- CONGIA = Licencia, despedida del servicio.

- CONJUNTAS = Parejas de bueyes uncidos.

- CONLOA = Loacion, aprobacion.

- CONOSCUDO = Conocido.

- ConOzudo = Lo mismo que conoscudo.

- CONQUERIR = Conquistar, ganar, adquirir.

- CONSETMENT = Consentimiento, voluntad.

- CONSTRENGAR = Obligar, compeler.

- CONTA = Cuenta.

- CONTADO = Condado.

- CONTESCA $=$ Acontezca.

- CONTESCER $=$ Acontecer.

- CONTRARIA = Contradicion, oposicion.

- CONTRARROLOR = Contralor de la casa real.

- CONTREITO = Ympedido para el trabajo.

- Conveniencia ó CONVINENCIA = Convenio, pacto.

- Convenient (en tal) = De manera, ó forma que, etc.

- CONYUGIO = Matrimonio.

- CORDERUNAS = La piel y lana de los corderos.

- CORMANO = Primo hermano.

- CORSERAS = Las inmediaciones de un pueblo ó sus arrabales.

- CORSIER ó CORSER = Caballo á propósito para la guerra.

- CORRAL = El sitio destinado en los pueblos para depositar las prendas embargadas á los deudores.

- CORRIBLE = Corriente, hablando de la moneda.

- COSIMANT ó COSIMENT = Alimentos, comida.

- COSIMENT (vasallo de) $=$ Criado ó soldado mantenido por el señor ó ricohombre.

- COSTAGE $=$ Cesta, gasto.

- COSTERIA = Lo perteneciente á la custodia de los campos.

- COSTIERO = Guarda de campos.

- COSTREITA = Consteñimiento, coaccion.

- COTO = Multa.

- COTOS = Ordenanzas municipales y las penas establecidas en ellas.

- Cozuelo = Yngenio de caza.

- CREADERo = Creado.

- CREBANTAR = Quebrantar.

- CREDOR ó CREEDOR = Acreedor.

- CreEduero = Creible, hombre que merecia fé.

- CREMAS = Quemarse. 
- CRIAZONES = Criaturas, hijos de corta edad.

- CRIEBAS = Quebrar; especie de maldicion, como quiébrese, pártase por medio tu cuerpo.

- CRISIlluCORT = Pecha de luz ó alumbrado con que los villanos contribuian á los señores solariegos.

- CRISTIANEGo = Lenguaje ó cosa de cristianos.

- CRISUELO = Candil; cierta pecha semejante á la llamada escuranina.

- CRUeza = Crueldad.

- CuARTER ó CUARTEL = Vease quarter.

- CUARTERA = Tierra dada en arrendamiento con la condicion de recibir el propietario la cuarta parte de la cosecha.

- CuATRO PIES (mueble de) $=$ Cuadrúpedo doméstico.

- CUBDICIAR = Codiciar.

- CUBIERTA = Engaño, fraude.

- CUCISTA = Cobranza, crédito.

- Cuend $=$ Conde.

- Cuentra = Contra.

- Cuesta = Costilla, espalda. Costa, gasto.

- CUGIR = Coger, asir, recaudar.

- CuILlar = Observar.

- CUILlER, CUILLIR ó CUILLDRER = Cobrar, recaudar.

- CUILLIDOR $=$ Cobrador, recaudador.

- CUINo = Cuño para la moneda. Cuña.

- CUITRE (buey) = Buey en venta puesto á prueba uncido con otro para conocer sus fuerzas.

- Culgar ó CUILGar = Lo mismo que cuiller.

- CURIAR = Cuidar, guardar.

- CURosia = Cuidado, diligencia.

- Curoso = Cuidadoso, diligente.

- Chalabardanos = Nombre que se daba á los pueblos que no confinando con la Bardena, tenian, sin embargo, derecho á sus pastos.

- CHANDRIO = Hombre aplicado, laborioso.

- CHAPITEL = Alhóndiga.

- DAgONDUCHO = Aguaducho.

- DAILIS = Darles

- DALIEN, DAILli ó DAILLENDE = Lo mismo que aillént.

- DAMPNADO = Damnificado, condenado, castigado.

- DAQUENT = Lo mismo que aquend.

- DEBANT $=$ Antes, delante.

- DEBDOR $=$ Deudor. 
- Debegadas ó DEVegadAS = Varias veces. Vease begada.

- DECEBIR = Seducir, engañar.

- DECEN = Número diez.

- DEFALLECIER = Faltar al cumplimiento de algun deber.

- DEFENDER = Prohibir.

- DEFER = Deshacer.

- DEFESA = Dehesa.

- DEILl = De él.

- DeINAR ó DEIGNAR = Dignarse.

- DEISAR = Dejar.

- Deleito = De ó del lecho ó cama. Vease leitera. Leito.

- Delgata = Pecha que pagaban los habitantes del pueblo de Caparroso con la llamada galleta hácia los años 1100 .

- Delmage = Cabador; debe decir mage, suprimiendo el artículo del.

- DEMANDADOR = Comisario.

- DEMIENTRE $=$ Mientras, entretanto.

- DENIAR = Lo mismo que deinar.

- DENOMINOSO = Ygnominioso.

- DENT $=$ De alli. Dentro.

- DEPUERTO = Diversion, entretenimiento.

- DerRaigar = Arrancar de raiz.

- DERSAR = Dejar.

- Desafiamiento = Desafio.

- DESAFIJAR = Desheredar.

- DESENT $=$ Desde luego.

- DESFALLECIER = Lo mismo que defallecier.

- DESFER = Deshacer.

- DESHEREDAR = Ademas de su acepcion comun, significaba despojar, desposeer.

- DESISCASE = Váyase, márchese.

- DESIDIR = Salirse, marcharse.

- DESITAR = Desposeer, quitar.

- DesnaturAdo = Desnaturalizado, desterrado.

- DESNUAR = Desnudar.

- DESONDRAR = Deshonrar.

- Despagamiento = Despego, desamor.

- DESPEITO $=$ Despecho.

- DESPERDRIA = Perderia, aniquilaria .

- DESPUILLAR = Despojar, desapropiar.

- DESQUe = Desde que, despues que, luego que.

- Desticillo = Gotera.

- DESTIN = Testamento.

- DESTIN EN UNO = Testamento de hermandad. 
- Destinamiento = Lo mismo que destin, testamento.

- Destreillo = Lo mismo que desticillo.

- DESUDILAR = Descargar, echar á tierra alguna cosa.

- DETAILLAR = Sacudir los árboles.

- DEU = Debe.

- DEUDA CEBERA = Deuda en cebada y otros granos.

- DEVANT $=$ Antes.

- DEVENIR $=$ Acontecer, suceder.

- DEVISAR = Disponer, ordenar, indicar, espresar.

- DI = De allí, desde allí.

- DIETA = Peonada, medida de tierra correspondiente á lo que un peon podia trabajar en un dia.

- DIFUGIO = Efugio.

- DISCENSION $=$ Disension.

- DISSO $=$ Dijo.

- Dito = Dicho, del verbo decir.

- DIVISA = Division, reparticion.

- DivisAment = Con division ó separacion.

- Do $=$ Donde. Doy, del verbo dar.

- DOBLEN = El número dos.

- DOCEN $=$ Doce.

- Dolis = Les doy.

- DOMAGE = Daño.

- DOMAYAR = Dañar.

- DONADIO = Donacion.

- DONARIO = Lo mismo que donadio.

- DONCAS = Dado caso que, á no ser que, pues que.

- DONO = Lo mismo que donadio.

- DORSO = Piel de la espalda de los animales.

- DRAPO = Paño, tela.

- DRECHURERO = Directo, en linea recta.

- DREITO = Derecho.

- DREITURERo = Recto, justo.

- DUBDADO = Dudoso.

- DUEINA = Señora, muger casada ó viuda.

- DUelo = Compasion, lastima.

- DULA = Lo mismo que adula. Vease tambien bestiario.

- ECHA = Contribucion.

- ECHANDRA = Muger casada ó viuda. Parece que en ciertos pueblos habia algunas 
particularmente destinadas con este nombre para dar fe de varios actos, para asistir á los partos y velar á los difuntos; tambien habia echandros.

- ECHANZON, ESCHANZON ó CHANZON = Copero de la casa real.

- ECHAUN ó ECHANDRO = Vease echandra.

- EINGAR = Ceñir la espada ú otra cosa.

- EISO = Eso.

- ElEGIDERO = Elegido, ó apto para serlo.

- EliDAR = El umbral de la puerta de la calle. Vease idár.

- EMBAIR ó EMBAYER = Ynvadir.

- EMBARGAR = Prohibir, vedar.

- EMBELUPAR = Envolver, ó cubrir alguna cosa.

- EMBEUDAR = Embeodar, embriagar.

- EMBRAVIR = Provocar, escitar quimera.

- EMEYO = Yngenio para cazar animales.

- EMPARANZA = Ejecucion de bienes.

- EMPARAR = Apoderarse de alguna cosa, tomar posesion de bienes ejecutados.

- EMPEINAMIENTO = Empeño de bienes.

- EMPLEgaS = Mercadurias.

- EMPLEITAS = Lo mismo que emplegas.

- EMPONZADO = Envenenado.

- EMPREINAR = Empreñar.

- EMPUES $=$ Despues.

- EMPUIGAR = Empujar.

- ENA = En la.

- ENANT $=$ Antes.

- ENANZO = Los trámites, curso y actuaciones judiciales de un proceso.

- ENCAESCIER $=$ Acaecer.

- ENCALZAR = Correr tras alguno, perseguirlo, alcanzarlo.

- ENCAOTAMIENTO = Cautela, astucia.

- ENCARA = Pero, ademas.

- ENCARTADO = Criminal contumaz ausente. Villano encartado: el que tenia pacto escrito con su señor sobre las pechas.

- ENCENS $=$ Censo.

- ENCONVENIENT = Convenio, pacto, condicion.

- ENCORRER = Yncurrir en alguna pena.

- ENCURAZADO = Soldado con coraza.

- ENCHERAR = Enterar, informar, comunicar.

- ENDUCTO $=$ Ynducido.

- ENDURIDO = Endurecido.

- ENEMIGA DE SU CUERPO = Mujer licenciosa, deshonesta.

- ENGEINO = Yngenio para cazar ó pescar.

- ENGORGAR = Entorpecerse el movimiento de la maquina de un molino, etc. 
- ENGORRAS = En guerras. Vease guerras.

- ENGROSAR = Protocolizar algun documento ó escritura. Hablando de los ganados, engordar.

- ENGUERRA ó ENGUERAS = Lo mismo que engorras.

- ENLORA = En aquella hora, entonces.

- ENOJADO = Enfermo, incomodado.

- ENOYAR = Enojar.

- ENQUESTA = Pesquisa, informacion.

- ENSEINAR = Enseñar, mostrar.

- ENSEMBLE = Juntos, unidos.

- ENSERIDO = Yngerido, incluido, insertado.

- ENSICAR = Secarse, marchitarse alguna planta.

- ENTA = Hácia tal ó cual parte.

- ENTEGRO = Entero, completo.

- ENTIDIA ó ENTIDA = Hasta que, etc.

- ENTONZ = Entónces.

- ENTREGO = Lo mismo que entegro.

- ENTRIDIR = Entrar.

- ENTRIR = Lo mismo que entridir.

- ENTRO = Hasta, hácia tal parte ó tiempo.

- ENTROAQUE = Hasta que.

- ENTRORIO ó ENTERRORIO = Entierro.

- ERMAR = Destruir, desamparar pueblos ó casas.

- ESCAICER = Lo mismo que encaescier.

- ESCALIAR $=$ Roturar tierras incultas.

- ESCALZAR = Cabar las viñas.

- ESCANCIANIA = Pecha que pagaban los escansianos. Vease.

- ESCANSIANOS = Ciertos pecheros, de tierra de Urroz, obligados á conducir la bebida para el ejército; tenían el título de escansianos del rey y como tales disfrutaban de algunas esenciones.

- ESCANSIAR = Beber.

- ESCOGENCIA = Escogimiento.

- ESCOLANO = Estudiante, sacristan.

- ESCOMENGADO = Escomulgado.

- EsCOSA = Doncella.

- ESCUILLIR = Escoger.

- ESCURANINA = Oscuridad; cierta pecha que se pagaba por la noche, ó despues de puesto el sol, para no interrumpir el trabajo de los pecheros durante el dia.

- ESCUSADO = Hombre esento de pechas ó contribuciones.

- ESCUSERO = Hablando de los perros, los que mordian sin ladrar.

- ESCUSO ó a ESCUSO = Lo mismo que ascuso.

- ESGART ó ESGOART = Consideracion; en esgoart, en consideracion; esgoardando, considerando. 
- ESGOARDAR = Considerar.

- ESIDA = Salida. Ejido.

- ESLEITO = Elegido.

- ESLEYER ó ESLEIR = Elegir.

- ESMOLAR = Amolar, afilar un instrumento cortante.

- ESNUAR = Lo mismo que desnuar.

- ESPANDAR ó ESPANDER = Esparcir, derramar.

- ESPARTARSE = Apartarse, separarse.

- ESPEINAR = Despeñar.

- ESPERAMIENTO = Espera, plazo.

- ESPLEITAR ó EXPLEITAR = Disfrutar de bienes y rentas.

- ESPORTICILLA = La muceta de los peregrinos.

- ESPUILlAR = Lo mismo que despuillar.

- ESTABLEDAT = Estabilidad.

- ESTATUTO = Establecido, establecimiento.

- ESTICOMEYO = Este intermedio. Vease comedio.

- ESTIDIER = Estar.

- ESTIEILlAR = Destilar; decíase cuando salia sangre de las heridas.

- ESTIN = Lo mismo que destin.

- ESTINAR = Hacer testamento.

- ESTONS = Entónces.

- ESTRANIAR = Enagenar.

- ESTRENIMIENTO = Diminucion.

- ESTRUCTION = Avestruz grande.

- ESTRUIR = Destruir.

- EsTRUZA = Avestruz.

- ETIDA = Lo mismo que entidia.

- EXEGUIR = Satisfacer, cumplir.

- EXIDO = Ejido.

- EXPRIMIR = Espresar, manifestar.

- EYURDEA = Contribucion sobre los cerdos. Véase quinta.

\section{F}

- FACENDERA = El trabajo en obras reales y concegiles.

- FACENDERIA = Lo mismo que facendera.

- FACER = Hacer.

- FACIENDO = Hediendo, asqueroso.

- FACINA ó FACHINA = Fagina de haces de mieses.

- FAGUA = Haga, del verbo hacer.

- FAILla = Tea para alumbrar.

- FAILLAR ó FALLAR = Hallar. 
- FAILlESCER = Faltar á una cita, llamamiento ú obligacion.

- FAINA = Faena.

- FAISA = Faja, cinta.

- FAISINA = Fagina. Choza de fagina ó paja.

- FAISO = Fajo, haz de paja.

- FAIZON = La hechura ó forma de cualquiera obra mecánica.

- FALAGO = Halago, seduccion.

- FALLAR = Hallar.

- FEAL = Fiel.

- FEALDAT, FIELIDAT ó FIELDAT = Fidelidad, usufructo, depósito.

- FEDIENT = Lo mismo que faciendo.

- FEITO, FEITA = Hecho, hecha, del verbo hacer.

- FENIESTRA = Ventana. Bocal, puerto ó desaguadero de la presa de un rio.

- FENO = Estiércol.

- FER $=$ Hacer.

- FERIR $=$ Herir.

- FERMA = Firme, estable.

- FERME $=$ Fiador.

- FERMEDAT = Seguridad, fianza.

- FESME = Ymperativo de fer, hazme.

- FEZO = Hizo.

- FIADOR DE CREITO = Fianza de justificar la demanda en juicio. Fianza de calumnia.

- FIELDAT = Lo mismo que fealdat.

- FINANZAS = Las rentas reales y la finalizacion de sus cuentas.

- FINCAR = Estar, ser, quedar; finque por traidor, se declara ser traidor; finque por hidalgo, se declara ser hidalgo.

- FINIESTRA = Lo mismo que feniestra.

- FIRMARSE = Asegurarse recíprocamente, darse fianzas.

- FISIGO = Médico.

- FIZ = Hice.

- FLOR ó FLUOR = El licor seminal.

- FO = Fué.

- FOLGAR = Holgar, divertirse, descansar.

- Folladura = Daño.

- FONSADERA = Lo mismo que alfonsadera.

- FORADAR $=$ Horadar.

- FORANIA = Cierto impuesto sobre el tráfico que hacian los estrangeros.

- FORAS = Fuera de, escepto, ó á escepcion de, etc.

- FORERO = Hombre instruido en los fueros.

- FORFEITURA ó FORFETURA = Delito de mucha consideracion.

- FORNECINO $=$ Hijo de casado y soltera. 
- ForNimiento $=$ Cumplimiento, completar el pago de una deuda.

- FORNO = Horno.

- FORRERO = El encargado de los equipages del rey, y de los bagages y forrages.

- FORTUNA $=$ Tempestad.

- FRAGOAR = Hacer, construir, fabricar.

- FRANCO ó FRANQUO = Hombre libre entre las dos clases de hidalgos y pecheros. Bienes francos ó franquos, libres de toda obligacion.

- FRAU = fraude.

- FREGAR = Conocer carnalmente á la muger.

- FREI = Flete, alquiler de una nave.

- FRESAR = Se decia de los molinos cuando no molian con perfeccion los granos.

- FRUITA = Fruta.

- FueIlla ó FUilla = Hoja.

- FUENTES (tener de) $=$ Ser padrino de bautismo.

- FUESA = Sepultura.

- FUILLA = Lo mismo que fueilla.

- FURT $=$ Hurto.

- FUST = Fué, fuiste.

- FUSTANIA = Cierta tela de uso comun.

G

- GAFERIA = Hospital de leprosos.

- GAFO = Leproso.

- Gailleta ó GOAilleta = Medida de liquidos, de la que tres y medio hacian un carapito. Barreño grande de madera para sacar agua de los rios, y otros usos.

- GAILURDiRUA ó GALliURDEA = Pecha sobre las gallinas que pagaban los pueblos de los valles de Burunda y Larraun.

- GALlETA = Pecha que no se esplica; la pagaban los habitantes del pueblo de Caparroso por los años 1100 , con otra llamada delgata.

- GANANCIA (hijos de) = Hijos naturales de soltero y soltera.

- GARAINON = Garañon.

- GARANA = Bosque artificial en jardines de recreo.

- GARGAZA ó GARRAZA = Muermo, enfermedad de los ganados.

- GARITAR = Guardar, velar, hacer centinelas.

- GARNIZON = Guarnicion de tropas.

- GARRANGA = Collar de hierro para los perros.

- GATO = Cerrojo ó cerradura de puerta.

- GAUZARI = Dañador.

- GAvaINAR = Agriarse ó volverse el vino.

- GAYOLA = Jaula.

- GEGOA ó GEGUA = Yegua. 
- GEINO ó GENIO = Yngenio, artificio mecánico.

- GENERO = El mes de enero.

- GENOILLA = Generacion, familia.

- GELO = Selo; non gélo vendió.

- GenOIllo = La pierna ó la rodilla.

- GESAR = Rayar, borrar, enmendar un escrito.

- GISO = Yeso.

- GLADIO = Pelea.

- GLESIA = Yglesia.

- GOAITAR = Lo mismo que garitar .

- GOIMANIENTO = Guarda, tutela.

- GOYERRIA ú OYARRIA = Nombre que daban los vascongados á Roncesvalles.

- GRAUT = Grandor.

- GRICEILLU = Candil.

- GRICEILLU-CORT = Pecha que pagaban los villanos á sus señores, reducida á suministrarles la luz mientras estos permanecian en sus señorios.

- GRIEVEMENT = Grave, amargamente.

- GROSO = Grueso, corpulento.

- GRUERA = Gruenza ó tolva de molino.

- GUARESCER = Curar una enfermedad.

- GUARIDO = Curado, sanado.

- GUARNIMIENTO = Adorno.

- GUARNIR = Guarnecer, adornar.

- GUERRAS = Llamábanse así los perjuicios que sufrian los fiadores cuando por falta de los deudores directos, se les embargaba alguna prenda viva y permanecia en poder del acreedor.

- GUESCA (SE) = Ymperativo de guarecer ó guardar: guarézcase, guárdese

- GUEZA = Pena, desgracia.

- GUISADO = Fácil, practicable.

- GUISAR = Aderezar, componer lo descompuesto.

- Hebrero = El mes de febrero.

- HECHA = Lo mismo que echa.

- HERBAGAR = Herbajar, dar pasto al ganado.

- HEREDAD PEINAL = Véase peinal.

- HeREDAD PLANA = Véase plana.

- HEREDAMIENTO $=$ Bienes raices.

- Hermandat = El conjunto de varios hermanos.

- HERMARSE = Ausentarse, desaparecer. Véase ermar.

- HI = Allí, ahí.

- HiA (dar vos) = Os daria, os daré. 
- HINIESTRA = Lo mismo que feniestra.

- HITO = Hábito religioso.

- Ho $=$ Donde.

- HODRAN = Oirán.

- HOMBRA = Sombra.

- HOMBRE DE LINAGE = Noble.

- HOMICIERO = Homicida. Véase buey omiciéro.

- HONDRADO = Honrado, condecorado.

- HONOR = Gobierno ó señorio de un pueblo.

- HONTA = Afronta, deshonra, injuria.

- HORRIO = Choza.

- HOSTAGE $=$ Rehen.

- HOSTẠL = La casa del Rey en lo que tocaba á la administracion económica.

- Hostelage $=$ Derechos de posada.

- HostieIllas $=$ Muebles de casa.

- Hostillamenta = Lo mismo que hostieillas.

- HUEILl = Peldaño ó escalon.

- HuEITANTA = Ochenta.

- HUEST $=$ Hueste, ejército, guerra.

- HuEvos = Uso, aprovechamiento, disfrute de una cosa en toda propiedad. En las escrituras de venta del siglo 14 solian decir los vendedores: «vendo para huevos y provecho de N. comprador, tal heredad».

- HUEY = Hoy.

- IDAR = El umbral de la puerta de la calle. Lo mismo que elidar, aunque en ésta palabra se halla el artículo el unido al sustantivo idar.

- ILLAGA = Aliaga.

- Illos = Ellos.

- IMPLIR = Llenar.

- IMUYADO = Palabra mal escrita por inviado ó enviado.

- INCENS $=$ Yncienso.

- INFANZON $=$ Noble, soldado de infanteria.

- INFANZON DE ABARCA = Véase abarca.

- INFANZONIA = Nobleza.

- INFIENT = Al finar tal tiempo, al infient de marzo, etc.

- INFLANTE $=$ Hinchado.

- INQUESTA ó INQUIESTA = Ynformacion.

- INVARNEDA $=$ Ynvernada.

- IRADO = Enojado.

- IRURDEA = Lo mismo que Eyurdea. 
- ISCAR = Salir.

- ISIDA = Lo mismo que esida.

- ISIDURA = Asadura.

- ISIENDO = Saliendo.

- ISIER = Hacer.

- ISIOS ó ISIOSE = Salióse.

- ISIR = Coger, agarrar. Salir.

- ISTAN = Salgan, saldrán.

- ITADIZO = Desterrado, prófugo.

- ITADO = Echado, arrojado, despedido.

- ITAR = Echar, arrojar, desterrar.

- ITAR EN CALONIA = Caer en pena, multar.

- ITAR FIANZA = Dar fiador.

- ITEN, ITENLI = Echen, échenle.

- ITO = Lo mismo que hito.

- JAZDRA = Estará.

- JUBERO = Persona encargada del cuidado de las medidas de tierras.

- JUDIENCO = Lenguaje ó cosa de judios.

- JUGE $=$ Juez.

- JURADO $=$ Yndividuo de ayuntamiento.

- JURADORES $=$ Los testigos.

- JURGAMIENTO = Juicio, sentencia.

- JUSTIERRA ó YUSTIERRA = Debajo de tierra.

$\mathrm{L}$

- LABOR = Pecha reducida á trabajar en las heredades del rey y de los señores territoriales.

- LACA = Escudilla de hierro de cabida de la vigesima parte de un robo de trigo; servia para medir los derechos de los molineros por moler los granos. Los derechos del molinero.

- LAMPADA = Lampara.

- LANZA = Como medida, era la distancia de un tiro de dardo; éste tiro se llamaba tambien treche ó trecho.

- LEBAR FUERO = Poner demanda judicial.

- LEBRIEL = Lebrel. Orden de caballeria.

$-\mathrm{LECH}=$ Leche.

- LECHUIGO ó LECHUGO = Mamanton, cosa de leche.

- LEDANIA = Cercania.

- LEDEAR = Lidiar. 
- LEGADOS = Juntos, congregados.

- LEGUMINA ó LEGUMNIA = Legumbre.

- LEISAR $=$ Dejar.

- LEITERA = El lecho ó cama.

- LEITO = Lo mismo que leitera.

- LENGOA = Habla, palabra, idioma.

- LEVAR = Llevar.

- LEXA = Manda, legado. Los terremos que dejan los rios.

- LEYAL $=$ Leal.

- LEYUNA = Leña.

- LEZINAR = Parage donde habia leña.

- LEZINEDO = Lo mismo que lezinar.

- LEZTA ó LEZDA = Contribucion semejante á la alcabala que se exigia sobre la venta de mercancias.

- LIBERA = Libre.

- LIENNA = Leña.

- LIGE = Feudo ligio.

- LINAGE (hombre de) $=$ Noble.

- LINDAR = Lo mismo que idar.

- LIZINO = Leña.

- LOAL = Lo demas.

- LOBERA = Abertura, especie de ventana ó claraboya.

- LOBRE = Oscuridad.

- LOGAR = Alquilar ó arrendar.

- LOGOR = Logro, usura.

- LOGRADOR = El que daba dinero á logro. Usurero.

- LOQUERO = El que daba y recibia en arrendamiento. El jornal que ganaba un peon.

- LORA $=$ Entonces en aquella hora.

- LUEINT ó LUEINE = Lejano.

- LUEYEN = Lo mismo que lueint.

- LUMBRE = Luz.

- LUR, LURES $=\mathrm{Su}$, sus.

- MAGE = Lo mismo que delmage, aunque en esta palabra se vé unido el artículo del al nombre mage.

- MAgUer ó maguera = Aunque, sin embargo, pero, pues que.

- MAILLAR = Golpear, maltratar.

- MAIllenta ó mailluentA = Dar ó tomar dinero á interes.

- MAILLEVAR = Lo mismo que maillente. 
- MALA = Maleta

- MALAUdie ó MALAUdia = Enfermedad.

- MALAVOZ = Oposicion judicial contra la propiedad ó posesion de bienes.

- MALEFICIO = Daño premeditado.

- MALEUTA = Lo mismo que maillenta.

- MALEZA = Malicia.

- MALMERIENT = Maltratar á alguna persona ó animal.

- MALUiTA = Lo mismo que maillenta.

- MALVEZTAT ó MALVEZAT = Hacer mal, pecado, delito.

- Malluelo ó mailluelo = Majuelo.

- MAMPARAR = Amparar.

- MANCEBA = Concubina.

- MANCIELLA = Cicatriz, herida.

- MANDADERO = Diputado, comisionado, enviado.

- MAÑERIA = Derecho del rey y de los señores territoriales á heredar á los villanos ó pecheros que morian sin hijos.

- MAOR = Mayor.

- MARCA = Represalia. Embargo por deudas.

- MARIDADA = Muger casada.

- MARQUERO = Deudor ausente afianzado, y su fiador.

- MARRUECO = Morueco.

- MASCLO = Masculino.

- MAYORAL = Alguacil.

- MAYORDOPNE = Mayordomo.

- MAYORIO = Mayorazgo.

- MAZONERO = Albañil.

- Meailla ó meaja = La menor moneda que se conocia.

- MEANDADO = Caminante á pié.

- MEANEDO, MEANERO ó MEYANEDO = Medianero, juez arbitrador.

- MEANEDO (clamar a) = Comprometer en árbitros.

- MECER = Mover, incitar, dañar.

- MEGE = Médico.

- MEge DE LAS PLAGAS = Cirujano.

- MeIllar = Parecerse, asemejarse.

- MEILlaria = Se pareceria ó asemejaria.

- MeitadenCo = Por mitad. Pan meitadenco: trigo mezclado por mitad con cebada ó avena.

- MEISME = Mismo.

- MELLOR = Mejor.

- MEMBRADO = Hombre capaz, instruido.

- MENDAR = Enmendar.

- MENGOA = Escasez, falta. 
- MENUZARIA = Menudencia.

- MERCADERO $=$ Mercader.

- MERINDAGE = Lo perteneciente á la merinia.

- MERINIA = Los derechos y atribuciones de los merinos.

- MERINO = Empleo público de autoridad con varias atribuciones en cada merindad de las en que estaba dividido el reino de Navarra.

- MeSECILlO, MESECilla ó MESICILla = Hombre ruin y muger de malas costumbres.

- MESIEILLO = Lo mismo que mesecillo.

- MESIONES ó MISIONES = Gastos.

- MESNADERO = Caballero noble al servicio del rey con obligacion de mantener caballo y armas.

- MESQUINO ó MEZQUINO = Villano, indigente.

- MEST = Pena, tristeza.

- MESTER = Menester.

- METER = Poner.

- MEYO, MEYA = La mitad.

- MIENTES (parar) = Reflexionar, considerar.

- MienTRE ó MIENTRES = Mientras.

- MierCA = Compra ó venta en el mercado.

- MILIA = Millar.

- Milite = Hombre de armas.

- MINERA = Mina.

- MisacANTANO = Clerigo ordenado de misa.

- MISAS = Lo mismo que mesiones.

- MISERACION = Misericordia.

- MOBLE = Mueble.

- MOLINO TRAPERO = Batan.

- MONTATICOS $=$ Montazgos.

- MORATICillo = Mulato lechal.

- MOSIRAR = Mostrar, manifestar.

- MOTALAGE = mudalafe: oficio destinado en algunos pueblos para el cuidado de los pesos y medidas.

- MOTE $=$ Palabra.

- MUDADO (sacar hombre al) = Sustituto que podia trabajar en el campo tanto como el que lo ponia en su lugar.

- MUEBLE DE CUATRO PIES = Lo mismo que cuatro pies.

- MUEILla = Muela, rueda de molino.

- Muillad De Pluvia = Decíase de la tierra ablandada por la lluvia.

- MUITO = Mucho.

- MUILla = Lo mismo que mueilla.

- MUNDARIA = Muger mundana, disoluta. 
- NADAL $=$ Navidad.

- NAFEgA = Provision de comida.

- NAORA = Noria.

- NEBODA = Nieta.

- NEGAR = Anegar, ahogar.

- $\mathrm{NI}=$ Equivalia en muchos casos á la partícula conjuntiva y: «os doy todo lo que tengo en Artabia ni en sus términos».

- NIEGUO = Negar.

- NOCEDO ó NOGEDO = Nogal, nogueral.

- NOCER ó NOSCIER = Dañar.

- NOMPNADO ó NONMADO $=$ Nombrado, especificado.

- NOPNAR $=$ Nombrar.

- NOSCO $=$ Nos, nosotros.

- NOVENA = La novena parte de las multas que correspondia á los alcaldes en varios pueblos, quedando para el fisco las ocho novenas restantes.

- NUILl = Ninguno, nada.

- NUIT $=$ Noche.

- $\mathrm{O}=$ En algunos casos significa donde.

- OBIENTE CAUSA = Véase causa hobiente.

- OBIES $=$ Hubiese.

- OBLIDO = Olvido.

- OBOS = Huevos de gallina y otras aves.

- OBRIR = Abrir.

- OCTOR = Actor.

- ODE, OND, ONDE = Donde, por tanto.

- ODIDOR = Oidor, oyente.

- ODRAN = Oirán.

- OIO $=$ Ojo.

- OL $=$ O le.

- OLOGAR = Alogar.

- OLSOCIA = O le ensucia.

- OMBAZENDUAVARIA = Pecha semejante á la de salvedat.

- OME = Hombre.

- OMICIERO = Homicida. Véase buey omiciero.

- OND = Donde, de donde.

- ONDRA = Honra. 
- ONSO = Oso

- ONT = Lo mismo que ond.

- ONTA = Lo mismo que honta.

- ONTADO = Deshonrado, afrentado, agraviado.

- OPELANDA = Hopalanda.

- OPIL $=$ Torta.

- OPILARINZADA = Pecha de tortas y vino, cuyo nombre se deriva de opil, torta, y arinzada, medida de vino.

- ORDEN (hombre de) $=$ Monge, religioso.

- ORGUE = Organo.

- ORTO = Huerto.

- OsSO $=$ Hueso.

- OSTADiAS = Pecha que pagaban al rey las villas de Etayo y Olejua.

- OSTAR = Quitar, retirar inconvenientes ó dudas.

- OSTELAGE = Lo mismo que hostelage.

- Ostillas ú OSTEIllas = Lo mismo que hostieillas.

- OYARRIA = Lo mismo que Goyerría.

- OYENZA $=$ Oyr.

- Ozteinto = Pecha que no se esplica, sino que la pagaban los pueblos del valle de Arce.

- OzTERATE = Cierta especie de pecha que pagaban los labradores del valle de Atéz.

- PADACiTOS (caballeros) = Parcioneros. Caballeros que entre varios poseian un collazo ó villano pechero.

- PAGO = Pavo.

- PAGUAR = Pagar.

- Pailla ó PAlla = Paja.

- PAILlAR = Pajar.

- PALENE = Estacada, seto.

- PALMADA = Darse las manos, segun se usaba, á la conclusion de algun contrato. Privilegio que tenia la ciudad de Estella para tomar de cada saco de trigo que se vendia en su mercado lo que cabia en la palma de la mano, para el culto de San Andres.

- PAN = Pan, trigo.

- PAN MeITADENCO = Véase meitadenco.

- PARADO = Convenido, especificado.

- PARAMIENTO = Ordenanza, convenio.

- PARARSE MAL = Sentirse mal, estar en guerra.

- PAREIlla = Pareja, matrimonio.

- PAREIlla (hijos de) $=$ Los hijos de matrimonio. 
- PARTIDA = Parte, porcion. Ser parte en algun negocio.

- PARTIDAS = Las partes interesadas en algun negocio. Reinos, territorios: en las partidas de Castilla, Aragon, Francia, etc.

- PARTIN = Partirse, separarse.

- PASADA = La distancia de un paso.

- PASIMENTO = Pasto de ganados.

- PASTICERIA = Viandas de pasta, pasteleria.

- PATERnOSTRE = Cuenta de rosario.

- PECER = Dañar.

- PECIAR = Malear, alterar; falsificar; decíase de la moneda corrible non peciada, etc.

- PEDIDO = Pedir las pechas y contribuciones.

- PEgNora = Prenda embargada.

- PEgNORAR ó PIGNORAR = Tomar prendas.

- Peguillarero $=$ Pupilo en tutela.

- PEgunteria = Pez, resina.

- PEILleRIE = Argolla de hierro con que se sujetaba por el cuello á los que por algun delito se esponian á la vergüenza pública.

- PEIlloso = Cuero al pelo.

- Peinaduera = La hembra en edad de concebir.

- PEINAL (heredad) $=$ Tierra afecta á alguna obligacion ó empeño.

- PEINDRA = Prenda tomada a un deudor; lo mismo que pegnora.

- PEINDRAR ó PENDRAR = Prendar, embargar; lo mismo que pegnorar.

- PEINO = Lo mismo que peindra.

- PEITA = Pecha.

- Peita pleiteada = Pecha tasada y reducida á cantidad fija.

- PEITAR = Pechar.

- PEITO = El pecho, parte del cuerpo del hombre y los animales.

- PELEYA = Batalla, pleito.

- PELOTA = Pelota. Bala de cañon de artilleria.

- PENAdo = Pesaroso.

- PENDRAR = Lo mismo que peindrar.

- PENSAR = Solia decirse por cuidar, mantener, alimentar.

- PERDIDO = Perdidóso.

- Pertiga ó Piertega = Pértica. Vara.

- PERTIGADOR = Medidor de tierras, agrimensor.

- PESQUERIR = Pesquisar, indagar.

- PESQUIRIR = lo mismo que pesquerir.

- PETICION = La accion de pedir, particularmente las pechas.

- PIDIMIA = Epidemia, peste.

- PIGNORAR = L.o mismo que pegnorar.

- Pillarte = Hombre á pie para el servicio de los caballeros armados. 
- PimiEnTA = Pecha ó contribucion que pagaban las aljamas de los judios al rey de $\mathrm{Na}$ varra.

- PindiTON $=$ Pedido, derrama, contribucion.

- PlaCENTERA = Voluntad, consentimiento.

- PlACto = Pacto, convenio.

- Plaga = Llaga, herida.

- Plana (heredad) = Libre de toda obligacion.

- Plaura ó palaura = Palabra.

- PlaURA PORFIDIA = Disputa porfiada y tenaz.

- Plazdo ó plazto = Plazo.

- PLEgAR = Recoger, reunir, congregar.

- Pleiteada = Véase peita pleiteada.

- Pleitesia = Pleito, pleitear.

- PLENERO = Pleno, completo.

- Pluvia = Lluvia.

- POBREDAT $=$ Pobreza.

- POLMONA = Enfermedad de los ganados.

- Pollairero = Oficio de la cocina del rey para el cuidado de las aves.

- POMADA = Sidra, y el vino mezclado con agua.

- PORA = Para.

- PORDRA = Pólvora.

- PORIDAT $=$ Secreto.

- PORQUeRIA = Manada de puercos.

- PORTAGO = Portazgo.

- PORTEGADO = Portal.

- POSEDESCER $=$ Poseer.

- POSEDIR = Lo mismo que posedescer.

- POSTAL = Travesaño ó barra para cerrar las puertas.

- POZON $=$ Veneno.

- POZONADOR = Envenenador.

- PREgAR = Rogar.

- PREgOVOS = Os ruego.

- PREMIDURA = La segunda prensadura que se hacia de la uva y el licor que resultaba de ella; llamábase tambien vinaca.

- PRENDEDERO $=$ Prendador.

- PRENDER = Tomar, coger, recibir.

- PRENGAR = Lo mismo que prender.

- PRESENES = Tomar posesion de alguna cosa.

- PRESIER = Lo mismo que prender.

- PRESION $=$ Prision.

- PRESO ó PRISO = Tomado, recibido. Aprisionado.

- PRESTAMERo = Comendador. Sustituto del señor ó gobernador de un pueblo. 
- PRestameria = El cargo de prestamero.

- PRESTAMIENTo = Lo mismo que prestameria.

- PREYUdIT $=$ Perjuicio.

- PREZAR = Valuar, tasar.

- PRIMIR = Esprimir, prensar.

- PRISIER = Lo mismo que prender.

- PROB = Cerca, próximo.

- PROBAÑo $=$ Cercano.

- PROBEITO $=$ Provecho.

- Profaso ó PROfazo = Cuidado, duda, consulta.

- Prosmano ó PROSIMANO = Lo mismo que probaño.

- ProveIR = Proveer, determinar, mandar.

- Publialment $=$ Públicamente.

- PUDATE = Especie de maldicion, huélate el aliento.

- PUINIR = Castigar.

- PUINO = Puño de la mano.

- PUYADA = Subida, la accion de subir.

- PUYO = Altura.

- QUADA = Cada.

- QUADREILLO = Ladrillo.

- QUANTIA = Cantidad.

- QUAR = Que, porque, pues.

- QUARTER ó QUARTEL = El subsidio ó donativo voluntario que las Cortes de Navarra concedian al rey para gastos del Estado; llamábase quarter porque se pagaba por cuartas partes del año.

- QUARTERA = Lo mismo que cuartera.

- QUEJADAMENT = A toda prisa ó diligencia.

- QUEREBANTAR = Quebrantar, romper.

- QUERIENZA = Querer, amar.

- QUIERE = Cualquiera.

- QUIÑON ó QUINON = Porcion, parte; se decia de las tierras incultas que se repartían entre los vecinos de un pueblo para cultivarlas.

- QUINTA = Contribucion sobre la cria de los cerdos que pastaban en los montes del rey, reducida á dar una cria de cada cinco; llamábase tambien quinta eyurdea ó yurdea.

- QUISQUADUNA = Cualesquiera.

- QUITAMENT $=$ Libremente.

- QuiTAMIENTO = Carta de pago.

- QUITANZA = Lo mismo que quitamiento.

- QUITAR = Libertar de una obligacion. 
- QUITIO = Quito, libre.

- RABAL $=$ Arrabal.

- RANCURA = Lo mismo que arrencura.

- RANZONAR $=$ Rescatar.

- RARET = Cosa menuda.

- RASA = Raspadura en lo escrito.

- RASTOILLO = Rastrojo.

- RASURA = Lo mismo que rasa.

- RAZONADOR = Abogador, procurador; lo mismo que Bocero.

- REBEILLAR = Resistencia á las órdenes de la autoridad. Rebeillar peinos se decia cuando el embargador de prendas encontraba resistencia en el deudor para entregarlas.

- RECAUDA = Resguardo, seguridad, garantia por escrito.

- RECEGADA = Rezagada.

- RECIDEVALLEN = El pueblo ó monasterio de Roncesvalles.

- RECOGNOSCENCIA = Reconocimiento; cierta pecha que pagaban los hijos de los villanos á los señores, cuando aquellos heredaban las heredades pecheras de sus padres, en señal de reconocimiento del Señorio.

- RECORSO $=$ Recurso.

- RECUDIR = Acudir, repetir.

- RECUILGAR ó RECUEILGAR = Acoger, amparar.

- REDOMBA = Redoma.

- REDRAR = Escluir, apartar.

- REDUPTABLE = Grande, poderoso; el muy reduptable señor, se decia, hablando del rey.

- REGANTRA = Queja.

- REGLATERO = Regaton.

- REGNA = Riñon.

- REISMO = Reino. Resma de papel.

- REITAR = Reiterar; restituir.

- RELEVAR = Conllevar.

- RELIEVO = Descargo, alivio.

- REM = Nada, ninguno.

- REM (en toda) = En lo demas, en todas las cosas.

- REN = Lo mismo que rem.

- RENCUROSO = Quejoso.

- RENCURA = Lo mismo que arrencura.

- RENDA $=$ Renta. 
- RENDER $=$ Rendir, dar cuentas.

- RENDIDA (Fiador de) = Fianza que daba el obligado á la devolucion de prendas embargadas.

- RENDITAS $=$ Entregadas.

- RENEGA = Reniega, el monte llamado despues Perdon entre Pamplona y Puente la Reina.

- RENES $=$ Riñones.

- RENTADOR = Arrendatario.

- RENUI $=$ El acto de restituir ó devolver una cosa.

- RENVOI $=$ Lo mismo que renui.

- REPTAR = Retar, citar á juicio.

- REQUESTA = Súplica, peticion, requerimiento.

- REQUISTA = Lo mismo que requesta.

- RES = Lo mismo que rem.

- RESAVIDO = Desagraviado, defendido.

- RESCRIBIR = Escribir dos ó mas veces una órden ó carta.

- RESONA = Rumor, noticia.

- RESORT = El derecho de soberania y homenage que se reservaban los reyes cuando daban en feudo algun pueblo con la jurisdiccion.

- RESTANZA = Resto de una cantidad.

- RESTOILLO = Lo mismo que rastoillo.

- RETENIENZA $=$ Retencion.

- REVENIDA = Renta, producto de una hacienda.

- RIBERA (sobiendo á) = El acto de acometer un perro saltando para morder.

- RIEDRA (fiador de) = Lo mismo que rendida.

- RIEN = Lo mismo que rem.

- RIENDER = Entregar.

- RIGUAR = Regar.

- RIGUO = Rio.

- RISCO = Riesgo.

- ROA = Robo, medida de granos.

- ROBERIA ó ROBEYA = Robo, rapiña, y la cosa robada.

- RODERO = Molinero.

- ROGARIA = Ruego, súplica.

- ROLDEAR = Rondar.

- ROMAINER $=$ Quedar, permanecer.

- ROMERO = Peregrino.

- ROMO = Lo mismo que romero.

- RONZAS = El pueblo ó monasterio de Roncesvalles.

- ROSTOL $=$ Lo mismo que rastoillo.

- RUA $=$ Calle.

- RUANO = Hombre que habitaba en el pueblo ó calle dedicado á las artes, á 
diferencia del villano pechero labrador que vivia en el campo ó fuera del pueblo en sus arrabales.

- RUEDA = Molino.

- RUMERO ó RUMEO = Lo mismo que romero.

- RUNA = El rio Arga.

- RUSTICO = Villano ó labrador pechero.

- SABIDOR = Sabio, entendido en alguna materia.

- SABOR (haber) $=$ Tener, llevar á bien.

- SABRIDAMENT = Sabidamente, á sabiendas.

- SABUDAMENT = Lo mismo que sabridamente.

- SACA = Contribucion sobre la estraccion del reino de trigo, vino y otros frutos.

- SACUA = Lo mismo que saca.

- SAGRAMENT = Juramento.

- SAGRIAMENT = Lo mismo que sagramént.

- SAILLIDOR (asno) = Garañon.

- SAILLIR = Salir.

- SAINA = Saña, ira.

- SALGAR = Lo mismo que saillir.

- SAlVA (caer en) = No haber probado lo bastante en un proceso el acusador contra el acusado.

- SALVARSE = Sincerarse, justificarse judicialmente.

- SALVEDAT = Salutacion; especie de pecha que pagaban los villanos á sus señores, reducida á darles una comida, ó cena, en el primer dia que llegaban á sus señorios y tomaban posesion. Observábase particularmente con los abades de los monasterios. Fianza de salvedat, la que se daba para el cumplimiento de algun contrato. Significaba tambien la libertad que se concedia á una persona de hacer una cosa sin limitarle tiempo, y así se decia á su salvedat, esto es, á su voluntad, á su comodidad.

- SANCHA = Véase Baeza.

- SAQUAR = Quitar, escluir, separar.

- SAQUET $=$ Saco.

- SARPILlERA $=$ Arpillera, tejido grueso.

- SARRAIlla = Cerraja.

- SARRAzON ó SERrazon = Cerca ó fortificacion de un pueblo.

- SAYNA = Lo mismo que saina.

- SAYON = Especie de alguacil.

- SAYONIA = El oficio de sayon y los derechos que exijia por el ejercicio de sus funciones.

- SECE = Número diez y seis. 
- SEDicilla = Trono, solio, sala donde se oian los pleitos, y el tribunal que los decidia.

- SEguescer = Proseguir. Acaecer ó suceder.

- SEINA CAUdAL = El estandarte real.

- SEINAL ó SEÑAL = Enseña ó estandarte. El caballero que tenia en honor ó mandaba un pueblo por el rey, y á cuyo cargo estaba el estandarte real.

- SEINNORIA MAOR = Señoria mayor, la autoridad suprema del rey.

- SEL = Tierra acotada para pasto ó arbolado. Parage donde se cubilaba el ganado.

- SEMANAPEON = La obligacion de trabajar los hombres pecheros un dia á la semana en las heredades del rey y de los señores territoriales.

- SEMBLE (en) = Lo mismo que ensemble.

- SEMEILLABLE = Semejante.

- SEMIEILlO = La mitad.

- SEMPNAR = Sembrar.

- SENES $=$ Sin.

- SENT $=$ Sed.

- SEPNADO $=$ Sembrado.

- SEPNAR = Lo mismo que sempnar.

- SEQUA = Seca, leña seca.

- SERCIEILlo = Cello ó aro de cuba ó de otra vasija.

- SEREDES = Sereis.

- SERLI $=$ Serle.

- SERVAR = Observar ó cumplir un deber.

- SERVIENT $=$ Sirviente.

- SEYENDO $=$ Estando.

- SEYENTES = Bienes sedientes.

- SEYER = Estar, ser.

- SIED = Lo mismo que sedicilla.

- SiEILlO ó SEYELlO = Sello.

- SIENDOS = Sendos.

- SIERO = Suero.

- SIERVO = Criado, no esclavo.

- SIETO = Seto.

- SIGLO = Se usaba en la acepcion de mundo en los contratos para significar su duracion: mientras el siglo durare.

- SILVA = Selva.

- SINES = Lo mismo que senes.

- SIRGANO = Bodega de sidra.

- SISANTENA, SIXANTENA ó XIXANTENA = Multa que se imponia por heridas llamadas medio homicidio; decíase sisantena porque se componia de tres números 60 , esto es, de 60 sueldos, 60 dineros y 60 meajas.

- SO = Su, soy, bajo, debajo. 
- SOBERANIDAD $=$ Soberania.

- SOBIER = Estar, permanecer.

- SOCIAR = Ensuciar. Véase Olsocia.

- SOFRESCER = Dar espera para algun pago, ú otra cosa.

- SOFREZCAR $=$ Lo mismo que sofrescer.

- SOGONT $=$ Segunt.

- SONETE $=$ Cascabelillo.

- SOPIENDO = Sabiendo.

- SORTIEILLA = Sortija, anillo.

- SOSAGADO = Sosegado.

- SOSTRA = Suela ó planta de zapato. Cuando los ejecutores judiciales embargaban ó tomaban posesion de bienes, usaban la ceremonia de aplicar á las puertas de las casas ejecutadas las sostras de sus zapatos.

- SOTERO = Guarda de sotos.

- SOTERRAR = Enterrar.

- SOVENT $=$ Con frecuencia, de costumbre.

- $\mathrm{SOZ}=$ Debajo.

- SOZMERINO $=$ Teniente de merino.

- SUA $=$ Su, suya.

- SUBDOSO = Palabra ofensiva.

- SUERT = Suerte, parte de una hacienda dividida.

- SUBYECCION $=$ Sujeccion.

- SUBITANO $=$ Repentino.

- SUFRIENZA ó SOFRIENZA = Espera, plazo para pagar.

- SUITO = Suelta.

- SUMER = Bestia de carga.

- SUOR $=$ Sudor.

- SUPERVIO = Sobervio, hombre díscolo, malo.

- TABLA = Mesa. Oficina donde se cobraban los derechos de estraccion é introduccion de mercancias.

- TAEXADA $=$ Tasada, valuada.

- TAFureria ó TAFuraria = Casa de juego.

- TAILla = Tasa. Contribucion vecinal que se pagaba en el pueblo de Viana.

- TAILLADA = Cortadura ó trinchera de fortificacion.

- TAILLADOR = Escultor.

- TAILLANDERO = Sastre.

- TAILlAR = Cortar, partir, talar árboles.

- TAILlAzON = Corte, tala de árboles. 
- TAINIR = Tañer las campanas.

- TAMAINO = Tamaño.

- TARANCLERA = Talanquera.

- TAYAR = Lo mismo que taillar.

- TENENZA ó TENIENZA $=$ Posesion.

- TENIENTE $=$ Poseedor.

- TERAR = Quitar, destruir.

- TERmINADO $=$ El distrito de un pueblo.

- TERMINERA = Límite del distrito de un pueblo, y algunas veces el mismo distrito como terminado.

- TERNA = Tendrá, del verbo tener.

- TERRIBLES (bienes) = Bienes raices.

- TESTADRIZ $=$ Testadora.

- TESTE $=$ Testigo.

- TeSTIMONIO $($ facer) $=$ Ser testigo, poner testigos.

- TIDA = Lo mismo que entidia.

- TIER $=$ Tierra.

- TIERA = La tercera parte.

- TINIA = Tinaja, cubo.

- TIRAR = Retirar, evitar, separar.

- To = Todo, toda.

- TODAVIA = Toda la vida .

- TOILLER, TOILLIR ó TOLGAR = Quitar, tomar.

- TONDEDOR $=$ Fundidor de paños.

- TOQUAR = Tocar, tañer.

- TOR $=$ Torre, fortaleza.

- TORCHA = Hacha para alumbrar.

- TORNA = Vuelta, repeticion.

- Torna a batailla = Apelacion en pleito.

- TORNADIZO = El judio ó moro convertido al cristianismo.

- TORNEAMIENTO $=$ Torneo.

- TORTEADO = Agraviado, perjudicado.

- TORTO = Tuerto, agravio, injuria, daño.

- TRANSPORTACION = Traspaso del dominio de una cosa.

- Trasainado = Se decia de los puercos que tenian mas de un año de edad.

- TRASFUNO $=$ Trashumar el ganado.

- TRASNOCHA = Ademas de su acepcion comun significaba particularmente el acto de trasnochar los ganados embargados en poder del acreedor.

- TRASNUITAR $=$ Trasnochar.

- TRAYA = Ymperativo de traer, traiga.

- TRAYER $=$ Traer.

- TREBEYAR ó TREBEJAR = Jugar, divertirse. 
- TREBOILLA = Cuerda para asegurar la carga en las caballerias.

- TREBUDO, TREHUDO ó TRIBUDO = Tributo ó censo.

- TRECHE = Distancia de un tiro de lanza. Véase lanza.

- TRESAL = Lo perteneciente al número tres.

- Treugua = Tregua.

- TRIBUdamento ó TREUDAmiento = Lo mismo que trebudo.

- TRO ó TROA = Hasta tal tiempo ó cantidad, etc.

- Troala = Hasta la, etc.

- TroAQue = Hasta que.

- TROBAR = Hallar.

- TRONZON = Trozo ó parte separada de alguna cosa.

- TROSA = Fardo ó lio de mercadurias.

- TROSEL = Diminutivo de trosa.

- TRUCHIMAN = Trujaman ó intérprete.

- TUEILliR ó TUlliR = Lo mismo que toiller.

- TUEITO = Lo mismo que torto.

- Tueleta $($ fer) = Desposeer, despojar.

- TUELGA = Ymperativo de toiller.

- TUELTAS $=$ Malos hechos.

- TUERTO (tener en el pleito) = Salir mal en la causa, perder el pleito.

- TUICION = Guarda, defensa.

- TUSO = Tuvo, del verbo tener.

- TUTO = Guardado, defendido.

- UBIAR = Estar.

- UNGLA = Uña.

- UNTADO = Ungido, consagrado, hablando de los reyes.

- USATICO = Uso, costumbre.

- VACA CORTA POR ASADURA = Contribucion ó pecha sobre la cria del ganado.

- VACA REGIS = Bajo este nombre pagaban los pueblos de Asarta y Villamera cierta pecha al rey.

- VAILIA = Bailio.

- Vaillia ó valia = Vale, valia; hablando del valor ó precio de una cosa.

- VALA = Valga.

- VALADAR = Vallado.

- VALDO = Válido, abonado, hablando de los fiadores. 
- VALEDUERO ó VALLEDUERO = Válido, firme, seguro, permanente.

- VALLUA = Valor, precio de una cosa.

- VARAILlA = Lo mismo que barailla.

- VARAYA = Lo mismo que barailla.

- VEDE = Ve, vea.

- VEGADA ó VEGUADA = Lo mismo que begada.

- VEILLOSO = Hombre llegado á la pubertad.

- VENDIDA = Venta, enajenacion de una propiedad.

- VEREDA = Especie de pecha antiquisima, cuyas circunstancias no se esplican.

- VERRAN = Vendrán. Verán.

- VEYER $=$ Ver.

- VIDA (dar) = Alimentar.

- VIENTRE = La piel de los animales.

- VIERBO = Palabra.

- VILUERTO = Cuerda, ó lazo, para atar las caballerias.

- VILLANO = Hombre pechero labrador; habia villanos del rey ó realengos, solariegos ó de Señorio y de orden ó abadengos ó de monasterios. Villano encartado: véase encartado. Villano quito: se decia de los que esclusivamente pertenecian al rey.

- VINACA = Lo mismo que premidura.

- VISTRAER = Expender, adelantar ó prestar alguna cantidad.

- VIT $=$ Vid.

- VOCERO = Lo mismo que bocero.

$-\mathrm{Y}=$ Lo mismo que hi.

- YACER = Estar.

- YANTAR = Comer; contribucion ó pecha llamada tambien cena, esto es, la obligacion de los pecheros de dar de comer ó cenar á los señores territoriales cuando estos iban á pernoctar en sus señorios. Véase salvedat.

- YAZDRA = Lo mismo que jazdrá.

- YEROM = Yero.

- YUBERO = El labrador que tenia un par de bueyes.

- YUDGADO = juzgado.

- YUDGE = Juez.

- YUDICIO ó IUDICIO = Juicio, sentencia.

- YUGE = Lo mismo que Yudge.

- YUGLAR = Juglar.

- YUGO = Nombre de una pecha que se pagaba segun el número de los bueyes de labranza. Yugo compuesto de dos bueyes llamado yugo entero.

- YURDEA = Lo mismo que eyurdea.

- YURGAMIENTO = El acto de juzgar. 
- YUS ó YUSO = Abajo, debajo.

- YUSTA = Segun. Justa ó yusta su conciencia.

- YUSTIERRA = Lo mismo que justierra.

Z

- ZABACEQUIA $=$ Guarda de los regadios.

- ZAFAINORIA = Zanahoria.

- ZALMEDINA = Oficio público de autoridad entre los moros.

- ZARAMPION $=$ Sarampion.

- ZEMITERIO ó ZEMITORIO = Cementerio.

- ZERMENAGE $=$ Lo mismo que cermenage.

\section{RÉSUMÉ}

Dans cet article, les auteurs font état de divers documents conservés à la Bibliothèque de l'Académie Royale d'Histoire et qui sont en relation directe avec les Archives de la Cour des Comptes.

C'est le motif pour effectuer différentes analyses et fouilles dans les archives, mais aussi sur le plan paléographique et diplomatique: d'un coté, dans deux manuscrits, rédigés au début du siècle dernier par José de Vargas y Ponce, dont le titre est: Documentos sacados del Archivo de la Camara de Comptos de Navarra. Indice de los mismos (Documents issus des Archives de la Cour des Comptes de Navarre, suivis de la table des matières de ces mêmes documents) (et dont l'information lui est parvenue par l'entremise de Joaquín Juan de Flores, selon la preuve trouvée dans une lettre qu'il lui envoie et qui est retranscrite dans l'étude). Et d'autre part dans un petit cahier manuscrit, écrit en 1853 par l'illustre archiviste José Yanguas y Miranda qui renferme un vocabulaire employé par la dite Institution et dont on fait la transcription correspondante.

Ainsi, bien que ce soit de manière concise, on a su réaliser une introduction sur l'évolution historique des Archives et de la Cour des Comptes, apportant une bibliographie particulièrement choisie.

\section{SUMMARY}

In this article, the authors present several documents kept at the Library of the History Royal Academy which are directly related to the Revenue Court Archives.

It is a reason for performing several analyses and investigations in the archives, but also for considering a palaeographical and diplomatic point of view. On the one 
hand, we study two manuscripts titled Documentos sacados del Archivo de la Camara de Comptos de Navarra. Indice de los mismos (Documents from the Navarra Revenue Court Archives. Index.), and redacted, at the beginning of the last century, by José de Vargas y Ponce who got the information through Joaquín Juan de Flores, according to an evidence found in a letter sent to him and transcribed in the study. On the other hand, we analyze a small manuscript notebook, written in 1853 by the famous archivist José Yanguas y Miranda, that contains the vocabulary used by the above mentioned Institution and which has also been retranscribed.

So, even if it is concise, this is an introduction to the historical evolution of the Archives and of the Revenue Court, that also brings a very selected bibliography. 